\title{
Fatores de risco associados à ocorrência de anticorpos anti-Leptospira spp. em cães do município de Monte Negro, Rondônia, Amazônia Ocidental Brasileira
}

\author{
[Risk factors associated with anti-Leptospira spp antibodies occurrence in dogs from Monte Negro County, \\ Rondônia, Brazilian Western Amazon]
}

\author{
D.M. Aguiar ${ }^{1,5}$, G.T. Cavalcante ${ }^{2,6}$, M.F.V. Marvulo ${ }^{3}$, J.C.R. Silva ${ }^{4}$, A. Pinter ${ }^{1}$, S.A. Vasconcellos ${ }^{1,5}$, \\ Z.M. Morais ${ }^{1}$, M.B. Labruna ${ }^{1}$, L.M.A. Camargo ${ }^{2}$, S.M. Gennari ${ }^{1,5}$ \\ ${ }^{1}$ Faculdade de Medicina Veterinária e Zootecnia - USP \\ Av. Prof. Dr. Orlando Marques de Paiva, 87 \\ 05508-900 - São Paulo, SP \\ ${ }^{2}$ Instituto de Ciências Biomédicas - USP \\ ${ }^{3}$ Faculdade de Medicina Veterinária - UNIP e UNIBAN - São Paulo, SP \\ ${ }^{4}$ Curso de Medicina Veterinária - Universidade Anhembi-Morumbi - São Paulo, SP \\ ${ }^{5}$ Bolsista do CNPq \\ ${ }^{6}$ Bolsista da CAPES
}

\begin{abstract}
RESUMO
Foram testados, pela técnica de soroaglutinação microscópica aplicada à leptospirose, 329 cães provenientes do município de Monte Negro, RO, dos quais 156 eram da área urbana e 173 da área rural. Simultaneamente foi aplicado questionário para verificar a existência de possíveis fatores de risco pela regressão logística. Abordaram-se questões referentes a idade, sexo, dieta, tipo de criação, ambiente, contato com outras espécies e hábito de caça. Foram detectadas reações com títulos $\geq 100 \mathrm{em} 27,3 \%$, com 90 cães positivos ao agente, das quais $23,7 \%$ eram da área (37/156) urbana e 30,6\% (53/173), da área rural $(\mathrm{P}>0,05)$. Os sorovares predominantes, reatores com títulos mais elevados, foram Autumnalis $(22 \%)$, Pyrogenes $(12 \%)$, Canicola $(10 \%)$ e Shermani $(7,5 \%)$. Cães com idade acima de 12 meses apresentaram maior ocorrência de anticorpos quando comparados aos cães mais jovens $(\mathrm{P}<0,05)$. Dentre os fatores de risco analisados, foram significativos a alimentação (dieta à base de ração comercial - odds ratio: 3,3; intervalo de confiança: $95 \%: 1,2-9,2 ; \mathrm{P}=0,02$ ) e o sexo (macho - odds ratio: 2,3 ; intervalo de confiança: $95 \%: 1,3-3,9 ; \mathrm{P}=0,003)$. Ressalta-se a ocorrência de reações para sorovares mantidos na natureza por animais silvestres.
\end{abstract}

Palavras-chave: cão, Leptospira spp., fatores de risco, Amazônia

\begin{abstract}
The microscopic agglutination test was applied to 329 samples taken from 156 dogs from urban area and 173 from rural areas of Monte Negro County, Rondonia State, Brazil, to determine anti-Leptospira spp. antibodies. A survey was concomitantly done to detect eventual risk factors thru the use of logistic regression. Studied variables were age, sex, diet, management, environment, contact with other species and hunting habit. Titers $\geq 100$ were detected in $27.3 \%$ (90/329) of the dogs, being $23.7 \%$ (37/156) urban and $30.6 \%$ (53/173) rural dogs. The most frequent serovars were Autumnalis (22.0\%), Pyrogenes (12.0\%), Canicola (10.0\%) and Shermani (7.5\%). Dogs older than 12 months showed higher positive frequencies than younger animals $(P<0.05)$. Risk factor were associated with commercial food as compared to homemade food (odds ratio: 3.3; 95\% confidence interval : $1.3-3.9 ; P=0.02)$ and associated with sex, with higher occurrence in males than in females (odds ratio: 2.3; 95\% confidence interval: $1.3-3.9 ; P=0.003$ ). It was emphasized the serological occurrence of serovars kept and spread in nature by wild animals.
\end{abstract}

Keywords: dog, Leptospira spp., risk factor, Amazon

Recebido em 23 de fevereiro de 2005

Aceito em 1 de novembro de 2006

E-mail: danmoura@aptaregional.sp.gov.br

Apoio: FAPESP 


\section{INTRODUÇÃO}

A leptospirose é uma importante doença infecciosa de cães, caracterizada por quadros febris com sintomatologia variável desde gastroentérica, hepática e renal, até neurológica (Wohl, 1996). Em cães, a infecção por Leptospira spp. também assume importância na saúde pública, decorrente da possibilidade de infecção em humanos (Acha e Szyfres, 2001).

No Brasil, os inquéritos sorológicos já realizados sobre a leptospirose em cães encontraram resultados variáveis, entre 3 a $30 \%$, e os sorovares mais freqüentes têm sido Icterohaemorrhagiae, Copenhageni, Canicola, Pyrogenes, Hardjo, Castellonis e Ballum (Furtado et al., 1997; Jouglard e Brod, 2000; Mascolli et al., 2002; Silva et al., 2004, Magalhães et al. 2006).

$\mathrm{Na}$ região norte do Brasil, a ocorrência de anticorpos anti-Leptospira spp. em cães ainda foi pouco estudada. $\mathrm{O}$ estado de Rondônia, precisamente o município de Monte Negro, apresenta características típicas de colonização, onde é observado o compartilhamento do ambiente por diferentes espécies animais, o que pode promover a associação e adaptação de agentes a novos hospedeiros (Aguiar, 2004). Portanto, acompanhar a evolução de determinadas doenças em regiões como fronteiras agrícolas amazônicas representa um desafio científico inegável, justificando a realização de estudos com ênfase em zoonoses tropicais e subtropicais.

Este estudo teve por objetivos estimar a ocorrência de anticorpos anti-Leptospira spp. em cães de ambientes urbano e rural e dos principais sorovares envolvidos, e avaliar os possíveis fatores de risco para a infecção, em cães do município de Monte Nego, RO.

\section{MATERIAL E MÉTODOS}

$\mathrm{O}$ estudo foi realizado no município de Monte Negro, RO, localizado a oeste da Amazônia Brasileira $\left(10^{\circ} 18^{\prime} \mathrm{Sul} ; 63^{\circ} 14^{\prime}\right.$ Oeste). Foram examinados 329 cães de idade e raças variadas, sendo 131 fêmeas e 198 machos, dos quais 156 eram da área urbana e 173 da área rural, provenientes de fazendas de criação de bovinos. Os parâmetros adotados para estabelecer o tamanho da amostra dos cães urbanos foram prevalência esperada de $50 \%$, precisão mínima de $7 \%$ e intervalo de confiança de $95 \%$, de um total de 671 cães residentes na área urbana. A amostra de 156 cães compreendeu o número médio de 1,5 cães por quadra (amplitude: 1-4 cães). Os cães do meio rural foram obtidos durante um estudo realizado na região em que avaliaram-se doenças reprodutivas em bovinos (Aguiar, 2004). Foram colhidas amostras de sangue de 173 cães que estavam presentes em 70 propriedades envolvidas no estudo, representando o total de cães presentes por ocasião das visitas. Os cálculos, para obtenção da amostragem dos cães, foram realizados com o auxílio do programa EPIINFO 6.04.

As amostras foram obtidas assepticamente por venopunção da cefálica ou jugular, com agulhas $21 \mathrm{G}$ apropriadas para tubos a vácuo. Os soros foram obtidos após a retração do coágulo e estocados a $-20^{\circ} \mathrm{C}$ até o momento das análises. Posteriormente, foram examinados por meio de soroaglutinação microscópica (SAM), efetuada em microplacas com leitura direta através de objetiva de longa distância (Galton et al., 1965; Cole Junior et al., 1973) com uma coleção de antígenos constituídos por leptospiras vivas, cultivadas em meio líquido de Ellinghausing; Mcolloug; Johnson; Harris (EMJH) modificado (Mascolli et al., 2002) contendo os sorovares: Andamana Australis, Autumnalis, Bataviae, Bratislava, Butembo, Canicola, Castellonis, Cinoptery, Copenhageni, Grippotyphosa, Hardjo, Hebdomadis, Icterohaemorrhagiae, Javanica, Panama, Pomona, Patoc, Pyrogenes, Sentot, Shermani, Tarassovi, Wolffi e Whitcombi. O sorovar considerado como o mais provável de provocar a infecção foi o que apresentou maior título no exame. O ponto de corte para a triagem foi a diluição de 1:100. Com os antígenos reatores na triagem, foi realizada a titulação dos soros por meio de uma série de diluições de razão dois. O título do soro foi a recíproca da maior diluição que apresentou 50\% de leptospiras aglutinadas no campo microscópico.

Na ocasião da colheita de sangue, aplicou-se um questionário sanitário com o intuito de verificar possíveis fatores de risco. Foram abordadas as variáveis idade, sexo, dieta (comida caseira ou ração comercial), vacinação e tipo de ambiente (rural ou urbano). Somente nos cães urbanos questionou-se a forma de criação (domiciliado ou com acesso à rua) enquanto nos cães do meio rural foram incluídos dados referentes ao tipo de criação 
bovina associada (corte, leiteira e mista) e hábito de caça.

O estudo de associação entre os resultados dos questionários e dos exames sorológicos foi feito em duas etapas. Na primeira etapa foi realizada uma análise univariada, utilizando o teste do quiquadrado ou o teste exato de Fischer. Na segunda etapa, realizou-se uma análise multivariada pela técnica de regressão logística, com as variáveis que apresentaram um valor de $\mathrm{P}$ menor que $20 \%$ $(\mathrm{P}<0,20)$ na primeira etapa (Hosmer e Lemeshow, 1989). No modelo final da regressão logística, foram classificadas como fator de risco as variáveis que apresentassem $\mathrm{P}<0,05$, com respectivos valores de odds ratio (OR) e intervalo de confiança (IC) de $95 \%$.

A idade dos cães também foi avaliada pelo teste do $\chi^{2}$ utilizando-se o nível de significância de $5 \%$ $(\mathrm{P}<0,05)$. As análises foram realizadas com $\mathrm{o}$ auxílio do programa EPIINFO 6.04 e SPSS 10.0 para Windows.

\section{RESULTADOS}

Houve reação com título $\geq 100$ em 27,3\% (90/329) dos cães testados na SAM, das quais $23,7 \%$ (37/156) eram de ambiente urbano e $30,6 \%$ $(53 / 173)$, de ambiente rural $(\mathrm{P}>0,05)$. No ambiente rural, 55,7\% (39/70) das propriedades estudadas apresentaram pelo menos um cão sororreagente. Dos cães soropositivos, ocorreram 20 casos de coaglutinação mas não foi possível determinar $o$ sorovar mais provável. Os sorovares detectados, com suas respectivas titulações e de acordo com o ambiente estudado, são apresentados na Tab. 1. Os sorovares Wolffi, Pomona, Hebdomadis, Copenhageni e Panama ocorreram apenas uma vez no ambiente rural e o sorovar Patoc, apenas uma no ambiente urbano.

Tabela 1. Cães reagentes à soroaglutinação microscópica para Leptospira spp. no município de Monte Negro, RO

\begin{tabular}{|c|c|c|c|c|c|c|c|c|c|c|c|c|}
\hline \multirow{3}{*}{ Sorovar } & \multicolumn{5}{|c|}{$\begin{array}{c}\text { Área rural } \\
(\mathrm{n}=156)\end{array}$} & \multicolumn{5}{|c|}{$\begin{array}{c}\text { Área urbana } \\
(\mathrm{n}=173)\end{array}$} & \multicolumn{2}{|c|}{$\begin{array}{c}\text { Total } \\
(\mathrm{n}=329)\end{array}$} \\
\hline & \multicolumn{3}{|c|}{ Título } & \multirow[b]{2}{*}{$\mathrm{n}$} & \multirow{2}{*}{$\%$} & \multicolumn{3}{|c|}{ Título } & \multirow[b]{2}{*}{$\mathrm{n}$} & \multirow{2}{*}{$\%$} & \multirow{2}{*}{$\mathrm{n}$} & \multirow{2}{*}{$\%$} \\
\hline & A & $\mathrm{B}$ & $\mathrm{C}$ & & & $\mathrm{A}$ & $\mathrm{B}$ & $\mathrm{C}$ & & & & \\
\hline Autumnalis & 4 & 0 & 1 & 5 & 9,4 & 8 & 7 & 0 & 15 & 40,6 & 20 & 22,2 \\
\hline Pyrogenes & 4 & 6 & 0 & 10 & 19,0 & 1 & 0 & 0 & 1 & 2,7 & 11 & 12,2 \\
\hline Canicola & 0 & 1 & 0 & 1 & 1,9 & 7 & 01 & 0 & 8 & 21,6 & 09 & 10,0 \\
\hline Shermani & 4 & 1 & 0 & 5 & 9,4 & 1 & 1 & 0 & 2 & 5,4 & 07 & 7,7 \\
\hline Butembo & 2 & 2 & 0 & 4 & 7,5 & 0 & 1 & 0 & 1 & 2,7 & 05 & 5,6 \\
\hline Hardjo & 2 & 3 & 0 & 5 & 9,4 & 0 & 0 & 0 & 0 & 0 & 05 & 5,6 \\
\hline Bratislava & 3 & 0 & 0 & 3 & 5,6 & 0 & 0 & 0 & 0 & 0 & 03 & 3,3 \\
\hline Grippotyphosa & 1 & 1 & 0 & 2 & 3,8 & 0 & 0 & 0 & 0 & 0 & 02 & 2,3 \\
\hline Icterohaemorrhagiae & 1 & 0 & 0 & 1 & 1,9 & 1 & 0 & 0 & 1 & 2,7 & 02 & 2,3 \\
\hline Outros* & 5 & 0 & 0 & 5 & 9,5 & 1 & 0 & 0 & 1 & 2,7 & 06 & 6,6 \\
\hline Coaglutinação & 8 & 4 & 0 & 12 & 22,6 & 7 & 1 & 0 & 8 & 21,6 & 20 & 22,2 \\
\hline Total & 34 & 18 & 1 & 53 & 100 & 26 & 11 & 0 & 37 & 100 & 90 & 100 \\
\hline
\end{tabular}

$\mathrm{A}=100$ a $200 ; \mathrm{B}=>200$ a $800 ; \mathrm{C}=>800 . \mathrm{n}=\mathrm{n}^{\mathrm{o}}$ total de cães examinados

* Sorovares Wolffi, Pomona, Hebdomadis, Copenhageni, Panama e Patoc.

Nos cães urbanos, a idade não interferiu com a ocorrência de anticorpos anti-Leptospira. Entretanto, nos cães rurais e na análise da totalidade dos cães, a ocorrência aumentou com a idade dos animais (>12 meses; Tab. 2).

Pela análise univariada, quando foram avaliados todos os cães, foram selecionadas para a regressão logística as variáveis: sexo, dieta e tipo de ambiente. Quando analisadas separadamente, por ambiente, no meio urbano selecionaram-se o sexo e a forma de criação, e no meio rural o sexo e a dieta. $\mathrm{Na}$ regressão logística, os machos apresentaram maiores chances de infecção que as fêmeas (OR: 2,3; IC 95\%: 1,3 - 3,9; $\mathrm{P}=0,003)$, assim como aqueles que se alimentavam de ração comercial quando comparados com os alimentados com comida caseira (OR: 3,3; IC 95\%: 1,2 - 9,2; $\mathrm{P}=0,02)$. Na análise por ambiente, observaram-se fatores de risco somente no ambiente rural. Os machos apresentaram maiores chances de infecção que as fêmeas (OR: 2,2; IC 95\%: 1,2 - 5,3; $\mathrm{P}=0,013)$, bem como os cães que se alimentavam de ração comercial (OR: 7,2; IC 95\%: 1,7 - 30,6; $\mathrm{P}=0,007)$. Os resultados são apresentados na Tab. 3 . 
Fatores de risco associados à ocorrência de anticorpos...

Tabela 2. Cães reagentes à soroaglutinação microscópica para Leptospira spp., de acordo com a idade no município de Monte Negro, RO

\begin{tabular}{lcccc}
\hline \multirow{2}{*}{$\begin{array}{l}\text { Idade } \\
\text { meses })\end{array}$} & Examinados & \multicolumn{3}{c}{ Soropositivos (\%) * } \\
\cline { 3 - 5 } & & Área urbana & Área rural & Total \\
\hline $0-12$ & 60 & $2(5,4) \mathrm{Aa}$ & $5(9,4) \mathrm{Ac}$ & $7(7,8) \mathrm{A}$ \\
$>12-24$ & 57 & $3(8,1) \mathrm{Aa}$ & $15(28,3) \mathrm{Bc}$ & $18(20,0) \mathrm{B}$ \\
$>24$ & 197 & $31(83,8) \mathrm{Bc}$ & $28(52,8) \mathrm{Bc}$ & $59(65,6) \mathrm{B}$ \\
Indeterminado & 15 & $1(2.7)$ & $5(9,4)$ & $6(6,7)$ \\
Total & 329 & 37 & 53 & 90 \\
\hline
\end{tabular}

*Valores seguidos por letras distintas maiúsculas na coluna e minúsculas na linha diferem entre si $(\mathrm{P}<0,05)$. As porcengens por idade foram calculadas sobre o total de positivos.

Tabela 3. Análise univariada e multivariada, segundo as variáveis estudadas nos cães amostrados e, separadamente, por ambiente urbano e rural do município de Monte Negro, RO

\begin{tabular}{|c|c|c|c|c|c|c|c|c|}
\hline \multirow{2}{*}{ Variável } & \multicolumn{2}{|c|}{$\mathrm{N}^{\circ}$ de cães } & \multirow{2}{*}{$\%$} & \multicolumn{2}{|c|}{ Univariada } & \multicolumn{3}{|c|}{ Multivariada } \\
\hline & Examinados & Positivos & & $\chi^{2}$ & $\mathrm{P}$ & OR & $\mathrm{P}$ & IC $(95 \%)$ \\
\hline \multicolumn{9}{|l|}{ Dieta } \\
\hline Comida caseira & 312 & 81 & 26,0 & & & 1 & & \\
\hline Ração comercial & 17 & 9 & 53,0 & 6,0 & 0,01 & 3,3 & 0,02 & $1,2-9,2$ \\
\hline \multicolumn{9}{|l|}{ Sexo } \\
\hline Fêmea & 131 & 24 & 18,3 & & & 1 & & \\
\hline Macho & 198 & 66 & 33,3 & 9,0 & 0,003 & 2,3 & 0,003 & $1,3-3,9$ \\
\hline \multicolumn{9}{|l|}{ Ambiente } \\
\hline Urbano & 165 & 37 & 23,7 & & & & & \\
\hline \multirow[t]{2}{*}{ Rural } & 173 & 53 & 30,6 & 1,9 & 0,160 & - & 0,180 & ---------- \\
\hline & \multicolumn{8}{|c|}{ Ambiente urbano: } \\
\hline \multicolumn{9}{|l|}{ Sexo } \\
\hline Fêmea & 63 & 10 & 15,9 & & & 1 & & \\
\hline Macho & 93 & 27 & 29,0 & 3,6 & 0,05 & 2,2 & 0,06 & $0,9-4,9$ \\
\hline \multicolumn{9}{|l|}{ Criação } \\
\hline Domiciliado & 51 & 8 & 15,6 & & & 1 & & \\
\hline \multirow[t]{2}{*}{ Acesso às ruas } & 105 & 29 & 27,6 & 2,7 & 0,10 & 2,0 & 0,10 & $0,8-4,9$ \\
\hline & \multicolumn{8}{|c|}{ Ambiente rural: } \\
\hline \multicolumn{9}{|l|}{ Sexo } \\
\hline Fêmea & 68 & 14 & 20,5 & & & 1 & & \\
\hline Macho & 105 & 39 & 37,1 & 5,3 & 0,02 & 2,5 & 0,01 & $1,2-5,3$ \\
\hline \multicolumn{9}{|l|}{ Dieta } \\
\hline Comida caseira & 163 & 46 & 28,2 & & & 1 & & \\
\hline Ração comercial & 10 & 7 & 70,0 & 7,0 & 0,10 & 7,2 & 0,007 & $1,7-30,6$ \\
\hline
\end{tabular}

$\chi^{2}=$ qui-quadrado, $\mathrm{OR}=$ odds ratio, $\mathrm{P}=$ probabilidade, $\mathrm{IC}=$ intervalo de confiança.

Outros fatores avaliados, como a dieta dos cães urbanos, o tipo de criação bovina e o hábito de caça nos cães rurais, não apresentaram significância estatística. Todos os cães recebiam regularmente a vacina anti-rábica. Para os outros agentes, incluindo Leptospira spp., a vacinação era feita esporadicamente, sem controle sanitário, e somente nos cães do ambiente urbano.

\section{DISCUSSÃO}

O presente estudo demonstrou a ocorrência de anticorpos anti-Leptospira spp. em cães de ambiente urbano e rural, do município de Monte Negro, RO, região promissora no desenvolvimento agropecuário da Amazônia Ocidental Brasileira. A ocorrência de anticorpos anti-Leptospira spp. foi observada em $27,3 \%$ dos cães do município estudado. Altas ocorrências foram também observadas em diferentes regiões brasileiras (Furtado et al., 1997; Jouglard e Brod, 2000; Mascolli et al., 2002; Azevedo et al., 2004; Silva et al., 2004; Magalhães et. al., 2006). Não houve diferença significativa entre as freqüências observadas nos ambientes rural e urbano. Devido à pequena área urbana da cidade, e ao acesso da grande maioria dos animais às ruas, os cães desse ambiente têm fácil contato com as áreas periurbanas, onde há sítios e pequenas propriedades rurais que podem favorecer o contato entre os cães e outros animais, possíveis reservatórios de leptospiras. 
No ambiente rural, $30,6 \%$ dos cães foram reagentes à SAM. Jouglard e Brod (2000), no Rio Grande do Sul, em área rural, constataram apenas 2,6\% de positividade. Acha e Szyfres (2001) enfatizaram a maior ocorrência de leptospirose nas regiões tropicais e subtropicais, decorrente da melhor viabilidade do agente nesse tipo de ambiente.

No ambiente urbano, a ocorrência encontrada está próxima à de outros centros urbanos, como as descritas por Furtado et al. (1997), no Rio Grande do Sul, e Querino et al. (2003), no Paraná, com 29 e $25 \%$ dos cães reagentes, respectivamente. Os resultados do presente estudo divergem dos apresentados por Acha e Szyfres (2001). O crescimento desordenado dos centros urbanos, com sérios problemas de saneamento básico e conseqüente proliferação de animais portadores de leptospiras, podem ser os responsáveis pela maior ocorrência do agente nessas cidades (Querino et al., 2003).

No presente estudo, predominaram os sorovares Autumnalis e Pyrogenes. Em inquéritos realizados no estado da Paraíba, também foi observada predominância do sorovar Autumnalis em cães e gatos (Alves et al., 2000; Alves et al., 2003; Alves et al., 2004; Azevedo et al., 2004).

No Brasil, o sorovar Pyrogenes foi primeiramente isolado de mamífero silvestre (Nectomys squamipes) por Santa Rosa et al. (1980), em áreas próximas à cidade de São Paulo, e também detectado sorologicamente em cães de outras localidades (Furtado et al., 1997; Jouglard e Brod, 2000; Querino et al., 2003; Silva et al., 2004, Magalhães et al., 2006). Os resultados do presente estudo, aliados aos da literatura, enfatizam a importância dos animais silvestres como reservatórios de leptospiras, atuando como fontes de infecções para os cães e, conseqüentemente, para o homem (Alves et al., 2000; Alves et al., 2004).

O sorovar Canicola foi relatado como o mais freqüente na espécie canina por Brihuega e Hutter (1994), na Argentina, por Furtado et al. (1997), no Rio Grande do Sul e por Magalhães et al. (2006), em Minas Gerais. Neste trabalho, esse sorovar foi o segundo mais freqüente entre os cães da área urbana. Yasuda et al. (1980), na cidade de São Paulo, isolaram o sorovar Canicola de cães de rua, confirmando o cão como fonte de infecção da leptospirose em centros urbanos.

O sorovar Shermani, o de maior freqüência neste estudo entre os cães rurais, também foi observado nessa região, em inquérito sorológico realizado nos bovinos das mesmas propriedades dos cães estudados (Aguiar, 2004). Esse sorovar foi isolado primeiramente de roedor silvestre (Proechimys semispinosus) no Panamá (University...,1997), sendo também freqüente em outro inquérito sorológico realizado na região norte do Brasil (Homem et al., 2001).

O sorovar Hardjo apresentou alta ocorrência entre os cães do meio rural. Os bovinos são considerados os hospedeiros de manutenção do sorovar Hardjo (Ellis, 1994). Nessa região, Aguiar (2004) observou o sorovar Hardjo como o mais freqüente entre os bovinos, confirmando a hipótese da transmissão entre as espécies bovina e canina.

Outros sorovares comumente detectados em cães, como Icterohaemorrhagiae, Copenhageni e Grippotyphosa, ocorreram em baixa freqüência, demonstrando a provável presença de fatores ambientais característicos da região (Alves et al., 2000).

Os cães alimentados com ração comercial têm maiores chances de adquirir a infecção que os alimentados com dietas caseiras. Nos cães do meio rural, também foi encontrado o mesmo resultado, sugerindo armazenamento inadequado da ração, o que pode favorecer a manutenção de possíveis reservatórios de leptospira. Esse fato poderia estar contribuindo para a maior exposição dos cães aos prováveis reservatórios, uma vez que os sorovares Autumnalis e Pyrogenes foram os mais prevalentes, ratificando a importância dos animais silvestres na epidemiologia da infecção leptospírica na região (Santa Rosa et al., 1980; Alves et al., 2000).

A maior chance de infecção verificada nos machos também foi observada por Rubel et al. (1997), na Argentina. Este resultado foi inesperado, pois em outros estudos conduzidos no Brasil (Furtado et al., 1997; Alves et al., 2000; Azevedo et al., 2004) houve igualdade na proporção de reagentes para ambos os sexos. 
Os cães com idade acima de 12 meses apresentaram maior número de reações à SAM que os cães mais jovens $(\mathrm{P}<0,05)$. Resultado semelhante também foi relatado por Rubel et al. (1997), Mascolli et al. (2002) e Azevedo et al. (2004), podendo ser justificado pela maior oportunidade de exposição ao agente entre os animais mais velhos.

Nos cães do meio urbano não se verificou associação entre a infecção e a forma de criação (acesso ou não às ruas). Em outros estudos, essa variável foi importante e apresentou associação com a presença de animais soropositivos, provavelmente pelo maior contato desses cães com possíveis reservatórios de leptospiras (Furtado et al., 1997; Rubel et al., 1997; Silva et al., 2004; Magalhães et al., 2006)).

Não se observou associação entre a atividade de criação bovina e o hábito de caçar dos cães rurais. A prevalência de anticorpos antiLeptospira spp. em propriedades com bovinos no município de Monte Negro foi de 95\% (82/86) (Aguiar, 2004), o que pode dificultar a caracterização da atividade de criação e até mesmo do hábito de caça como favoráveis à ocorrência da doença nos cães, pois esses animais poderiam estar sendo expostos às leptospiras por outras vias.

Alerta-se para a possibilidade de infecção no homem, tendo em vista as características regionais de fronteira agrícola amazônica.

\section{REFERÊNCIAS BIBLIOGRÁFICAS}

ACHA, P.N.; SZYFRES, B. Zoonosis y enfermedades transmisibles comunes al hombre y a los animales: bacterioses e micoses 3.ed. Washington: OPAS, 2001. 416p.

AGUIAR, D.M. Prevalência de anticorpos antiNeospora caninum, anti-Brucella abortus e antiLeptospira spp em bovino da zona rural do município de Monte Negro, rondônia: Estudos de possíveis fatores de risco: 2004. $118 \mathrm{f}$. Dissertação (Mestrado em Ciências) - Instituto de Ciências Biomédicas, Universidade de São Paulo, São Paulo.

ALVES, C. J.; CLEMENTINO, I.J.; OLIVEIRA, A.G.F. et al. Avaliação dos Níveis de aglutininas
anti-Leptospira em cães de caça na Paraíba, Brasil. Rev. Bras. Cienc. Vet., v.11, p.68-73, 2004.

ALVES, C.J.; ANDRADE, J.S.L.; VASCONCELLOS, S.A. et al. Avaliação dos níveis de aglutininas anti-Leptospira em cães no município de Patos - PB, Brasil. Rev. Bras. Cienc. Vet., v.7, p.17-21, 2000.

ALVES, C.J.; VASCONCELLOS, S.A.; MORAIS, Z.M. et al. Avaliação dos níveis de aglutininas anti-leptospiras em gatos no município de Patos - PB. Clin. Vet., v.46, p.4854, 2003.

AZEVEDO, S.S.; BATISTA, C.S.A.; ALVES, C.J. et al. Soroprevalência e fatores de risco para a leptospirose em cães do Município de Campina Grande, Estado da Paraíba. Arq. Inst. Biol. São Paulo, v.17, supl., p.543-545, 2004.

BRIHUEGA, B.; HUTTER, E. Incidencia de la leptospirosis en caninos de la ciudad de Buenos Aires. Vet. Arg., v.11, p.98-101, 1994.

COLE JUNIOR, J.R.; SULZER, C.R.; PURSELL, A.R. Improved microtechnique for the leptospiral microscopic agglutination test. Appl. Microbiol., v.25, p.970-980, 1973.

ELLIS, W.A. Leptospirosis as a cause of reproductive failure. Vet. Clin. N. Am.: Food Anim. Pract., v.10, p.463-478, 1994.

FURTADO, L.R.I.; FEHLBERG, M.F.B.; ÁVILA, M.O. et al. Prevalência e avaliação de fatores de risco a leptospirose canina no município de Pelotas, RS. Arq. Inst. Biol., v.64, p.57-61, 1997.

GALTON, M.M.; SULZER, C.R.; SANTA ROSA, C.A. et al. Application of a Microtechnique to the Agglutination Test for Leptospiral Antibodies. Appl. Microbiol., v.13, p.81-85, 1965.

HOMEM, V.S.F.; HEINMEMM, M.B.; MORAIS, Z.M. et al. Estudo epidemiológico da leptospirose bovina e humana na Amazônia Ocidental Brasileira. Rev. Soc. Bras. Med. Trop., v.34, p.173-180, 2001.

HOSMER Jr, D.W.; LEMESHOW, S. Applied logistic regression. New York: Wiley, 1989. $307 \mathrm{p}$.

JOUGLARD, S.D.D.; BROD, C.S. Leptospirose em cães: Prevalência e fatores de risco no meio 
rural do município de Pelotas, RS. Arq. Inst. Biol., v.67, p.181-185, 2000.

MAGALHÃES, D.F.; SILVA, J.A.; MOREIRA E.C. et al. Prevalência de aglutininas antiLeptospira interrogans em cães de Belo Horizonte, Minas Gerais, 2001 a 2002. Arq. Bras. Med. Vet. Zootec., v.58, p. 167-174, 2006.

MASCOLLI, R.; PINHEIRO, S.R.; VASCONCELLOS, S.A. et al. Inquérito sorológico para leptospirose em cães do Município de Santana de Parnaíba, São Paulo, utilizando a campanha de vacinação anti-rábica do ano de 1999. Arq. Inst. Biol., v.69, p.25-32, 2002.

QUERINO, A.M.V.; DELBEM, A.C.B.; OLIVEIRA, R.C. et al. Fatores de risco associados à leptospirose em cães do município de Londrina-RO. Semina, v.24, p.27-34, 2003.

RUBEL, D.; SEIJO, A.; CERNIGOI, B. et al. Leptospira interrogans en una poblacion canina del gran Buenos Aires: variables asociadas com la seropositividad. Rev. Panam. Salud Publ., v.2, p.102-105, 1997.
SANTA ROSA, C.A.; SULZER, C.; YANAGUITA, R.M. et al. Leptospirosis in wildlife in Brazil: Isolation of serovars Canicola, Pyrogenes and Grippotyphosa. Int. J. Zoon., v.7, p.40-43, 1980.

SILVA, W.B.; LOPES, A.L.S.; MODOLO, J.R. et al. Freqüência de aglutinina anti-Leptospira em cães, de acordo com o manejo de criação, na área urbana de Botucatu-SP. In: CONGRESSO BRASILEIRO DE CLÍNICOS DE PEQUENOS ANIMAIS, 25., 2004, Gramado, RS. Anais.... Gramado: ANCLIVEPA, 2004. p.87.

UNIVERSITY of Belgrade. Leptospira Home Page. [On Line]. 1997. Disponível em: $<$ http:/www.vet.bg.ac.yu/lepto/eti/serovars>. Acessado em 17 fev.1999

WOHL, J.S. Canine leptospirosis. Compendium, v.18, p.1215-1225, 1996.

YASUDA, P.H.; SANTA ROSA, C.A.; MYERS, D.M. et al. The isolation of leptospires from stray dogs in the city of São Paulo, Brazil. Int. J. Zoon., v.7, p.131-134, 1980. 